\title{
Design of Comprehensive Service and Innovation Incubation Platform for Individual and Private Enterprises in Zibo City
}

\author{
Baimei Yang ${ }^{1}$ and Dandan Wang, ${ }^{2, *}$ \\ ${ }^{1}$ Zibo Vocational Institute, Zibo, Shandong Province, China \\ ${ }^{2}$ Department of Information Engineering, Zibo Vocational Institute, Zibo, Shandong Province, China \\ *Corresponding author. Email:1562505660@qq.com
}

\begin{abstract}
In order to make full use of this industry source of colleges and universities, Zibo Network Technology Company and Zibo Vocational Institute jointly build a comprehensive service and innovation incubation platform for individual and private enterprises in Zibo City. The individual private enterprise association platform is non-profit, public welfare, and open, with 8 databases built to overcome the shortcomings of the existing platform, such as scattered data and asymmetric information. It is mainly composed of 4 sub-project groups: information construction and operation and maintenance group, and policy. Consultation and expert service group, innovation and entrepreneurship incubation and industrial park group, project docking and achievement transformation group. The platform has completed the information construction of individual private enterprise association service platforms, theoretical research and ideological and political improvement, innovation and entrepreneurship, and park incubation. In the future, it hopes to establish a complete information intelligent management system to enhance the soft and hard power of individual private enterprise associations.
\end{abstract}

Keywords: School city integration, Comprehensive service and innovation incubation platform for individual and private enterprises, Functions of the platform.

\section{INTRODUCTION}

Individual private enterprise associations are mass organizations composed of individual industrial and commercial households and private enterprise owners under the leadership of the Communist Party of China and the People's Government.In the process of the development of individual and private enterprises, the association of individual and private enterprises is an important organizational form to coordinate the government and private enterprises [1].

President Xi Jinping Said: "Individual workers' private enterprise associations should play a role as a bridge and link, and act as a popularizer of policies and regulations, a promoter of deepening reform, an enhancer of ability and quality, and an organizer of party building. Build a development platform, create a development environment, and earnestly do all work"[2].

\section{THE ROLE OF INDIVIDUAL PRIVATE ENTERPRISE ASSOCIATION PLATFORMS}

The role of individual private enterprise association platforms as follows: (1) mainly provide a group of service experts, and actively provide various free services to members; promote the mutual exchange of members, provide mutual services, and improve together. (2) Accept the commission of members, provide personnel training, provide technical support, assist in the completion of process improvement, promote enterprise informationization, automation, intelligent development and upgrading, and improve productivity. 


\section{DEFICIENCIES OF THE ORIGINAL INDIVIDUAL PRIVATE ENTERPRISE ASSOCIATION PLATFORM}

The association's own characteristics: Extensive membership and frequent exchanges. The original platform had limited functions and poor information transmission, which could not meet the demand.

Data dispersion: There are many forms, and the original platform has low entry efficiency; it is complicated to organize and has poor aggregation effect. Big data is difficult to analyze and provide decision support.

Information asymmetry: enterprises are looking for projects, projects are looking for enterprises; professional consultation is difficult.

\section{CONSTRUCTION OF NEW INDIVIDUAL PRIVATE ENTERPRISE ASSOCIATION PLATFORM}

\subsection{Platform Positioning and Research Areas}

\subsubsection{Third Level Heading Platform Positioning}

In order to give full play to the advantages of informatization, the spirit of the President's speech was put into practice, and now a service platform for promoting the development of individual private economy in Zibo City is developed and constructed. The comprehensive service and innovation incubation platform of individual and private enterprises in Zibo City is the project of the key R\&D plan of Zibo City in 2019. The platform is positioned as a non-profit public welfare platform, which serves individual private associations in Zibo City, benefits 451,000 congregations, assists the implementation of individual private association functions, and serves regional economic development and transformation and upgrading.

\subsubsection{Research Field}

First, platform informatization. We should give full play to the advantages of informatization and build a comprehensive service and Innovation Incubation Platform for individual and private enterprises.

Second, the construction of a think tank for private economic development. Fully mobilize industry experts in the association, give full play to the technical advantages of big data analysis, and build think tanks.

Third, technical service and achievement transformation. Build a vertical and horizontal smooth communication platform and transformation platform between members and banks, enterprises, universities and research institutes.
Fourth, innovation and entrepreneurship and incubator construction. We will steadily promote the traditional advantageous industries, actively cultivate new kinetic energy, and boost the transformation of new and old kinetic energy.

\subsection{Platform Function and Basic Database}

Zibo individual and private enterprise association's four major functions and platform main functions: Party building, arbitration, incubation, welding [3]. As shown in Figure 1.

The platform includes eight basic databases: intellectual property database, product database, supply and demand information database, office database, talent database, policy database, member / enterprise database and project database. Database can provide powerful data support for the platform, promote communication and cooperation among members, provide decision support, and realize information symmetry.

\subsection{Platform Operation}

\subsubsection{Platform Organization Structure}

The construction and operation of the platform adopts the project leader system, which consists of four sub project groups: the informatization construction and operation and maintenance group, the policy implementation and publicity and expert service group, the innovation and entrepreneurship incubation and industrial park group, and the project docking and achievement transformation group.

\subsubsection{Functions of Main Departments of the Platform}

Information construction and operation and maintenance group: it is mainly responsible for the construction and operation and maintenance of the information system of the platform, as well as enterprise information technology services.

Policy implementation and expert service group: it is responsible for setting up service expert group, implementing and publicizing national policies, providing consultation and training in business, law, finance and taxation, human resources, etc.

Innovation and entrepreneurship incubation and Industrial Park Group: it is responsible for promoting the construction of Industrial Alliance / Industrial Park, innovation and entrepreneurship cultivation and incubation, as well as the construction of district and county workstations to form models and demonstrations. 


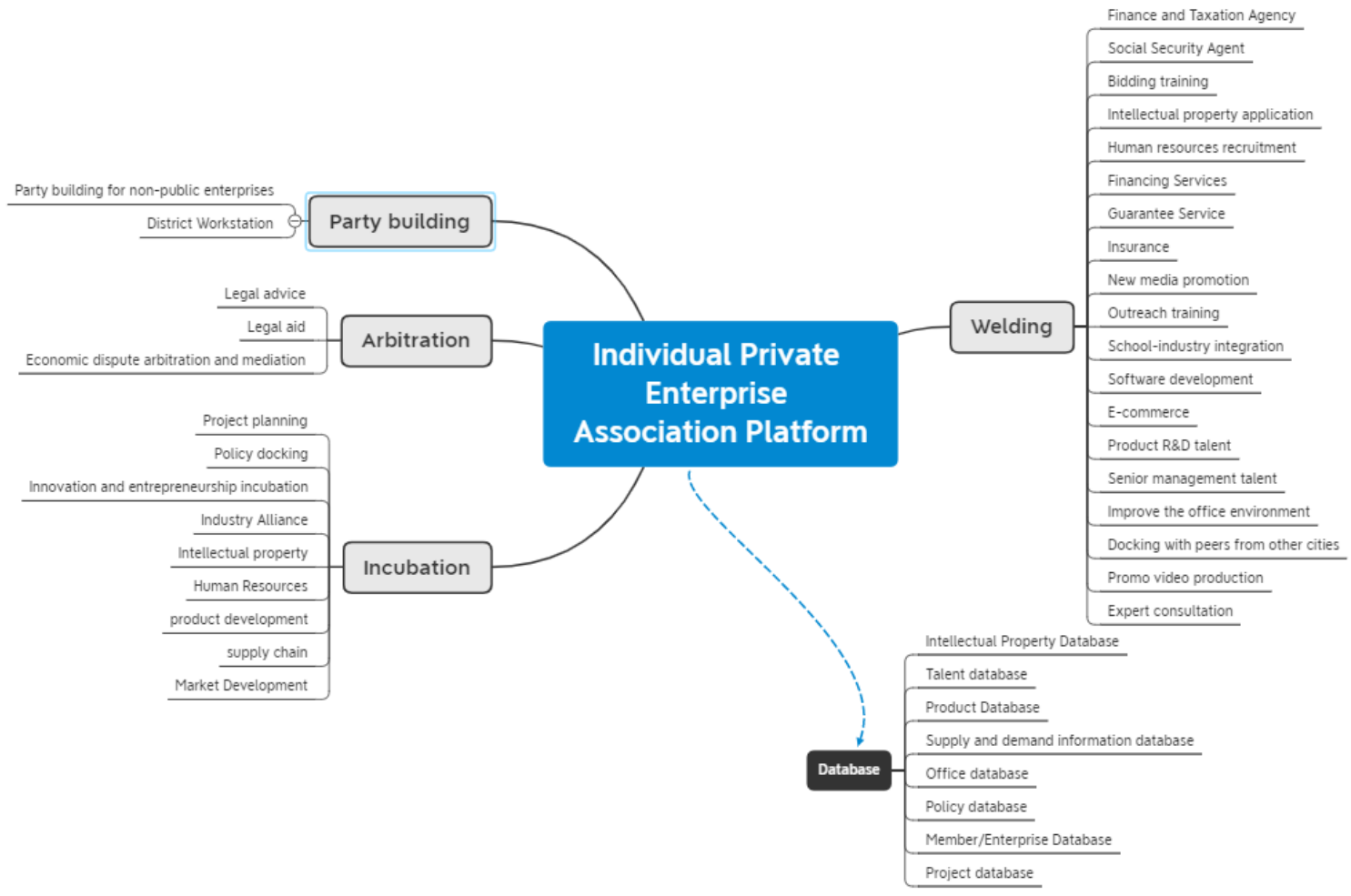

Figure 1. Platform $\mathrm{f}$ unction and basic database

Project docking and achievement transformation group: responsible for the project docking between the East and the west, internal communication and achievement transformation.

\subsubsection{Internal Management and Operation Mechanism of the Platform}

Management mechanism: the internal management of the platform mainly adopts the project leader system. Staffs are arranged according to four functional groups, and each group has a team leader, who is responsible for the overall work of the group. The platform implements an open operation management mechanism of "public welfare, inclusiveness, and comprehensiveness", with social benefits as the first priority to promote the development of Zibo's regional economy, especially the private economy, and take into account economic benefits.

Financing mechanism: during the platform construction period, the government, colleges and cooperative application units will jointly invest to complete the infrastructure construction. After the platform matures in the later stage, it forms a hematopoietic self-sufficiency mechanism and maintains the healthy operation of the platform through various kinds of income such as achievement transformation, information consultation, personnel training, technical support and service.
Personnel exchange mechanism: establish a benign personnel exchange mechanism, cultivate and reserve talents with the platform as the carrier; give full play to the advantages of Zibo Vocational Institute in terms of specialty strength, and strengthen the exchange and cooperation with co construction units and member enterprises.

Incentive and innovation mechanism: implement a fair and equitable distribution mechanism for each intelligent group, incentivize employees to complete tasks in accordance with the requirements of high quality in their work, and distribute those with strong tendencies and work hard. Encourage technical innovation of members, and reward innovative achievements that are beneficial to platform construction.

\section{RESEARCH TASKS AND ACHIEVEMENTS OF THE PLATFORM}

\subsection{Information Construction}

The technology accumulation and reserve are complete, the demand investigation has been completed initially, and the system architecture has been set up. The college and cooperative companies have rich experience in software R \& D, and the project team has undertaken 5 provincial and municipal science and technology development projects. 


\subsection{Theoretical Research and Ideological and Political Improvement}

Since 2019, it has focused on "enhancing learning, raising positions, deep reflection, and promoting rectification". It has studied and discussed important documents such as the 18th and 19th National Congress of the Party, the important spirit of the two sessions of each year, and the main points of the annual work.

\subsection{Innovation and Entrepreneurship and Park Incubation}

Achievements and experience have been achieved in Industrial Alliance / Park, innovation and entrepreneurship incubation, district and county workstation, and project docking between the East and the West.

\section{PLATFORM DEVELOPMENT PLANNING AND EXPECTED GOALS}

\subsection{Platform Development Plan}

Relying on the information platform, Zibo Association of individual and private enterprises will continue to strengthen the healthy development of the individual and private economy: within three years, the members have developed steadily, the number of social employment posts has gradually increased, and the contribution rate of Finance and taxation to society has increased steadily; the technological innovation achievements of the platform have been expanded to realize the transformation of about 200 technical achievements of members every year.

Integration of informatization and industrialization promotes development: it is necessary to combine informatization and industrialization at a high level, drive industrialization with informatization and promote informatization with industrialization, take a new road of industrialization, take platform as carrier, and cooperate with no less than 500 technical services every year, make full use of platform innovation achievements to serve enterprise development, accelerate the pace of enterprise production informatization, and improve enterprise productivity.

Summarize the promotion experience, spread the platform to other provinces and municipal individual private enterprise associations, and form a demonstration and radiation effect.

\subsection{Expected Construction Goals}

\subsubsection{Informatization Construction of the}

Service Platform of the Association of Individual and Private Enterprises
Build and improve the information intelligent management system, form 1 Platform $+\mathrm{N}$ databases, benefiting 451000 members.

\subsubsection{Promotion of Soft Power of Individual and Private Enterprise Association}

To implement the "menu service", focus on: (1) policy implementation and publicity, research and non-public economic theory research, foreign exchange, honest management, establishing the first. (2) Party building of individual private enterprises (non-public party building). (3) Legal aid, economic arbitration. (4) Project consulting and evaluation, financing services. (5) Intellectual property and technical services. (6) Employment training and human resource improvement. (7) Poverty alleviation in the west, and implementation of the poverty alleviation in the west: Golden Buckwheat Agricultural Planting Poverty Alleviation Project in Shizhu County, Chongqing; expansion of overseas industry connection.

\subsubsection{Promotion of Hard Power of Individual and Private Enterprise Association}

(1) Industrial Alliance Park: smart kitchen electric industrial park, Qilu e-commerce Valley phase 2, etc.

(2) Cultivation and incubation of innovation and Entrepreneurship: Jiaozhuang bakery chain brand, Zichuan Folk Park, etc.

(3) Brand cultivation: excellent product list, famous trademark and natural geographical indication products, etc.

(4) Construction of district and county workstation: complete the construction of other district and county workstations.

(6) To provide services for members, build a sharing bidding service platform, and jointly formulate internal bidding standards.

\section{CONCLUSION}

The platform for individual private enterprise associations is the first in China. It aims to serve the conversion of old and new kinetic energy, build bridges and bonds between the government and enterprises. Comprehensive service platform with satisfactory service, innovation and entrepreneurship incubation platform, policy implementation platform, technology transfer and achievement transformation platform.

\section{ACKNOWLEDGMENTS}

The study was supported by "Zibo city in 2019 focus on research and development program (school city fusi on development class) (Grant No. 2019ZBXC207)". 


\section{REFERENCES}

[1] Ding Xiaowei. Effective methods to maintain the vitality of sharing economy for tourism development [J]. Economic Research Guide, 2017 (36): $159-160+171$.

[2] Xi Jinping sent a letter to the Fifth National Congress of individual workers, emphasizing the importance of promoting entrepreneurship and giving play to the role of entrepreneurs, adhering to the real economy, implementing high quality development of [J]. Splendor and 2018 (02): 16-17.

[3] Yin Yucai. On the responsibility, function and role of the association of individual and private enterprises [J]. Farm economic management, 2006 (03):63-64. 